\title{
Bilateral Parovarian Cyst Complicated With Torsion In 12yrs Girl: Case Report
}

\author{
*Krishna Mandade ${ }^{1}$, Vishesha Yadav ${ }^{1}$, Shashant Singh ${ }^{1}$, Bhavthankar DP ${ }^{2}$, \\ Dr. Sarita deshpande ${ }^{3}$ \\ ${ }^{1}$ Junior resident, Department of $O B G Y,{ }^{2}$ Prof \& Head, Department of $O B G Y,{ }^{3}$ Associate proff. OBGY, Rural \\ Medical College, Pravara Institute Of Medical Sciences (DU), Loni, Maharashtra
}

\begin{abstract}
Torsion of uterine adnexa is an important cause of acute abdominal pain in which torsion of ovarian masses is quite common.

Parovarian cysts are benign cysts that are included within the subject of ovarian cysts due to their close position. They are seen rarely in children and are difficult to diagnose. It usually appears as an intra abdominal mass with a clinical picture of acute abdomen in the prepubertal period. The treatment is excision of the cyst with salvage of the ovary and fallopian tubes in uncomplicated cases whereas cyst excision with salpingooopherectomy may be required in case of adnexal torsion.

We present such a case of 12 yrs girl presented with acute abdomen with intra abdominal mass, diagnosed provisionally as a twisted ovarian cyst and undergone laprotomy; unilateral torsion of parovarian ovarian cyst $(10 \times 8 \mathrm{cms})$ involving right ovary with fallopian tube in pedicle with contralateral parovarian cyst (6x5cms) noted. Ipsilateral adenexal removal(including ovary and fallopian tube with twisted parovarian cyst showing gangrenous changes with enucleation of parovarian cyst on contralateral side with conserving left ovary and fallopian tube.
\end{abstract}

Conclusion: The paraovarian cyst may reach a large size and cause numerous complications, the most frequent of which is adnexal torsion, which could be prevented by an early diagnosis and surgical treatment.

Keywords: Paraovarian cyst, Adnexal Torsion, Salphingo-Oopherectomy.

\section{Introduction}

Cystic lesions of the ovary are most common during infancy and adolescence, which are hormonally active periods of development. ${ }^{1}$ Cysts are mostly non neoplastic in children and could be categorized as follicular, simple, hemorrhagic and corpus luteum cysts. ${ }^{2}$ The most common clinical presentation of ovarian cysts are abdominal pain, nausea and vomiting, and a history of previous episodes of similar pain and low grade fever. $^{3}$

A suggestion is made that components of the secundary Müllerian system, which include paraovarian/paratubal cysts, rete ovarii, endosalpingiosis, endometriosis, and endomucinosis, merit some consideration as to their possible role in ovarian tumorigenesis. ${ }^{4}$ Paraovarian cysts originate from the mesothelium and are presumed to be remnants of the mullerian duct and wolfian duct. ${ }^{5}$ Paraovarian cysts constitute about $10 \%$ of adnexal masses. ${ }^{6}$

While generally asymptomatic, they may rarely become clinically significant due to complications such as enlargement and/or torsion, hemorrhage, perforation and neoplasm. ${ }^{7}$ Treatment is enucleation of the cyst from the mesosalpinx without damaging the ovary and fallopian tubes when no complications have developed. However, salpingo-oopherectomy may be needed in complicated cases. ${ }^{8,9}$

\section{Case Report}

12yrs old girl presented in casualty department of Pravara Rural Hospital with complaining of severe pain in abdomen, palpitations and fever since 2 days. Pt. was apparently all right 2 days back when she developed pain in abdomen and mild fever which was insidious on onset, pain was sharp in nature developing palpitations at last.

Pt. reported to local doctor where she had done ultrasonography in which she was diagnosed as rt. Hemorrhagic cyst with simple cyst on lt. side.

Menstrual History: Menarche not attained.

There was past history of recurrent anemia due to unknown cause, personal history was not significant and there was no surgical intervention in past.

On examination: general condition of the pt. was stable, pulse: 140/min, BP: 100/60mmHg.

CVS/RS: within normal limits. 
P/A: abdomen distended, abdominal mass felt extending from umbilicus to pelvis, cystic in consistency, tens and tender, guarding and rigidity was present.

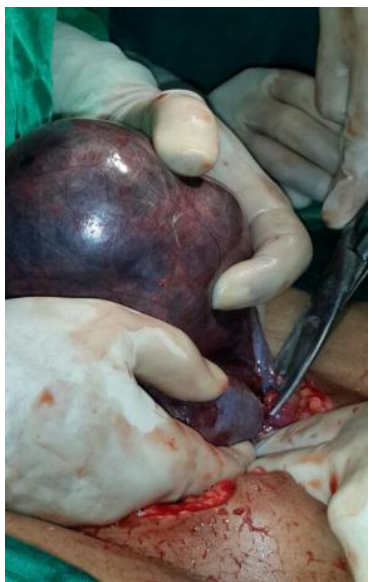

Figure 1: Salphingo-Oopherectomy

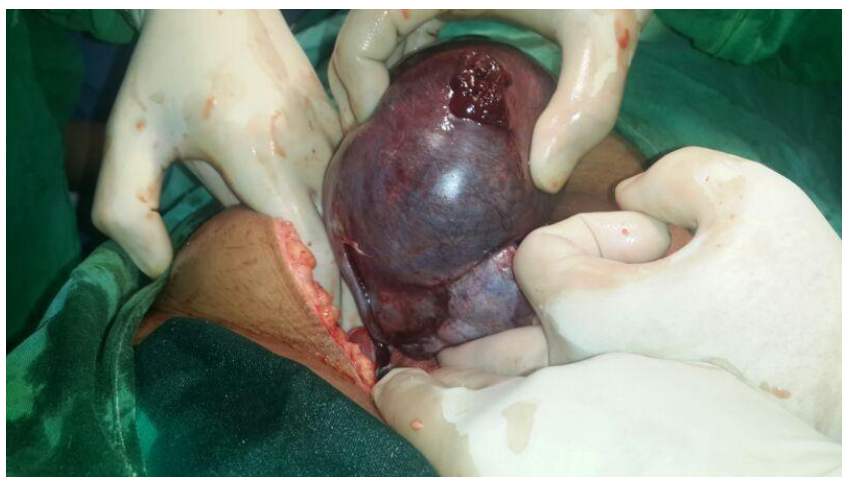

Figure 2: Hemorrhagic parovarian cyst with ovary

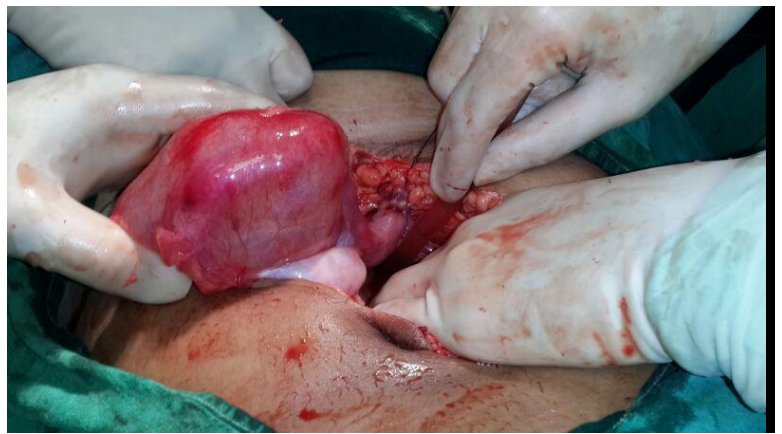

Figure 3: parovarian cyst on left side

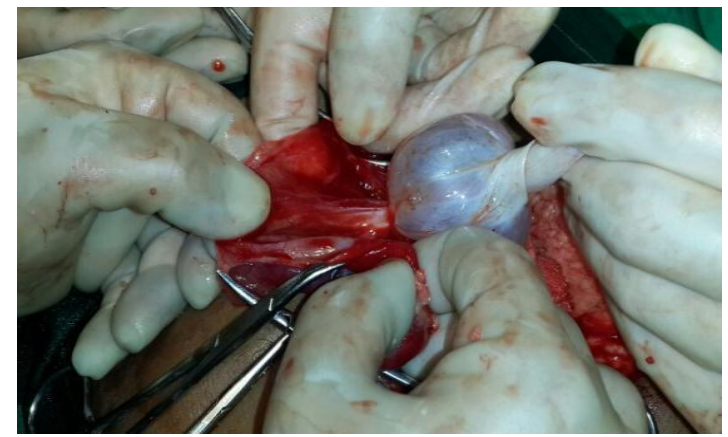

Figure 4: Enucleating parovarian cyst

Investigations: $\mathrm{Hb}-7 \mathrm{gm} \%$, TLC- WNL, LFT/RFT- WNL, Coagulation profile WNL.

USG: S/O right sided hemorrhagic cyst of size $10 * 9 * 5 \mathrm{~cm}$ not separately seen from ovary and left sided parovarian simple cyst of size $8 * 7 * 6 \mathrm{~cm}$ with no septations within it.

Treatment: Emergency exploratory laprotomy under GA performed in view of acute abdomen with ovarian cyst in suspicious of complication like torsion.

Intra-op findings: Right sided hemorrhagic cyst of size approximately $10 * 10 \mathrm{~cm}$ involving ovary \& fallopian tube in torsion Left sided simple parovarian cyst of approximately size $08 * 06 \mathrm{~cm}$ separate from ovary with no torsion observed.

Untwisting of rightparovarian cyst with Salphingo-Oopherectomy performed with simple enucleation of cyst on left side. Complete hemostasis confirmed.

Post operative was uneventful with one pack cell transfusion. Pt. discharged at $10^{\text {th }}$ post operative day.

Histopathology revealed a twisted hemorrhagic para-ovarian cyst with an oedematous fallopian tube with lining of cyst was composed of a single layer of tubal type columnar epithelium with ciliae and Signs of hemorrhagic infarct were observed in sections of the removed ovary.

\section{Discussion}

The incidence of paraovarian cysts among benign adnexal cysts is $17 \%$ to $33 \%$ of pediatric and adult cases. ${ }^{10}$ Paraovarian cysts are very uncommon in children, they are either asymptomatic and therefore not noticed in children or the diagnosis is made only when a complication such as torsion, perforation or bleeding develops.

Müllerian-lined cysts are common not only in the ovary, and are also frequently seen in paraovarian tissues with no apparent direct connection to the ovary ${ }^{4}$. Laughlin used the term "secondary Müllerian system" to designate structures lined by Müllerian epithelium found out of the uterus, cervix, and fallopian tubes. ${ }^{11}$

Paraovarian cysts are usually small in size, typical sizes reported are 1 to $8 \mathrm{~cm}$ in diameter. ${ }^{5}$ Larger lesions may reach $20 \mathrm{~cm}$ or more in diameter and become symptomatic exerting pressure and pain symptoms in the lower abdomen. ${ }^{12}$ Large cysts can lead to torsion of the adnexa inflicting acute pain as in our case. ${ }^{12}$ 
Paraovarian cysts are generally benign but may, on rare occasions give rise to borderline tumours and malignancy. ${ }^{13}$ Malignancy has been reported in 2-3\% of cases, ${ }^{14}$ although this is rare in lesions smaller than 5 $\mathrm{cm}$. Paraovarian cysts are usually single, but bilateral lesions have been reported. ${ }^{15}$

Because infundibulopelvic pedicle is longer in a child, torsion is a significant risk for larger cysts. Ovarian torsions are rare in the pediatric age group. In addition, atrophy of the ovary and other complications are common. ${ }^{1,3}$

Diagnostic ultrasound (sonography) is a noninvasive diagnostic imaging technique which is relatively sure technique to diagnose the parovarian cyst specially in emergency situations. Other than ultrasound, Magnetic resonance (MR) imaging is also definitive investigation but due to lack of time it was not the option in our case.

Being an uncommon surgical emergency with no definitive diagnostic signs the diagnosis is often delayed, resulting in irreversible damage to the fallopian tube. ${ }^{16}$

Cystectomy is recommended in cases of paraovarian cyst, and an attempt at ovarian salvage should be considered even in the event of torsion. The ovary should not be resected if the blood flow to the ovary is preserved in a twisted paraovarian cyst.

Salpingo-oopherectomy can be used for cases complicated by torsion with circulatory disturbance, ${ }^{10}$ as in our case.

Awareness of this condition is warranted to suspect and reach at an early diagnosis and enable the surgeon to perform a conservative surgery and salvage the fallopian tube. Several authors advocate detorsion of the pedicle with preservation of adnexal structures. ${ }^{17}$

\section{Conclussion} in children.

Our case report shows that the ovarian epithelial cystic neoplasm of paraovarian location may develop

In conclusion, paraovarian cysts can be seen at any stage of childhood and generally produce clinical signs when larger than $5 \mathrm{~cm}$. Ovary-preserving cyst excision is adequate for treatment in uncomplicated cases but salpingooopherectomy should be considered in complicated cases with circulatory disturbance or torsion, also taking the malignancy risk into account.

\section{References}

[1]. Brandt ML, Helmrath MA. Ovarian cysts in infants and children. Semin Pediatr Surg 2005; 14(2): 78-85.

[2]. Strickland JL. Ovarian cysts in neonates, children and adolescents. Curr Opin Obstet Gynecol 2002; 14(5): 459-65

[3]. Cass DL. Ovarian torsion. Semin Pediatr Surg 2005; 14(2): 86-92.

[4]. Dubeau L. The cell of origin of ovarian epithelial tumors and the ovarian surface epithelium dogma: does the emperor have no clothes? Gynecol Oncol 1999; 72(3): 437-42.

[5]. Kiseli M, Caglar GS, Cengiz SD, Karadag D, Yilmaz MB. Clinical diagnosis and complications of paratubal cysts: Review of the literature and report of uncommon cases. Arch Gynecol Obstet 2012, 285: 1563-69.

[6]. Barloon TJ, Brown BP, Abu-Yousef MM, Warnock NG. Paraovarian and paratubal cysts: preoperative diagnosis using transabdominal and transvaginal sonography. J Clin Ultrasound. 1966;24:117-22.

[7]. Perlman S, Hertweck P, Fallat ME: Paratubal and tubal abnormalities. Semin Pediatr Surg 2005; 14:124-34

[8]. Breech LL, Hillard PJ: Adnexal torsion in pediatric and adolescent girls. Curr Opin Obstet Gynecol 2005; 17:483-9.

[9]. Savic D, Stankovic ZB, Djukic M, Mikovic Z, Djuricic S: Torsion of malignant ovarian tumors in childhood and adolescence. J Pediatr Endocrinol Metab 2008; 21:1073-8.

[10]. Okada T, Yoshida H, Matsunaga T, Kouchi K, Ohtsuka Y, Takano H, et al: Paraovarian cyst with torsion in children. J Pediatr Surg 2002; 37:937-40.

[11]. Lauchlan SC. The secondary müllerian system revisited. Int J Gynecol Pathol 1994; 13(1): 73-9.

[12]. Varras M, Akrivis C, Polyzos D, Frakala S, Samara C. A voluminous twisted paraovarian cyst in a 74-year-old patient: case report and review of the literature. Clin Exp Obstet Gynecol. 2003;30:253-6.

[13]. Suzuki S, Furukawa H, Kyozuka H, Watanabe T, Takahashi H, Fujimori K. Two cases of paraovarian tumor of borderline malignancy. J Obstet Gynaecol Res 2013;39:437-41.

[14]. Honore L, O’Hare K. Serous papillary neoplasms arisiring in paramesonephric paraovarian cysts. Acta Obstet Gyneco Scand 1980;59:525-8.

[15]. Genardy R, Parmley T, Woodruff JD. The origin and clinic behaviour of the paraovarian tumor. Am J Obstet Gynecol 1977;129:873-80.

[16]. Wheeler JE. Diseases of the fallopian tube. In: Kurman RJ, editor. Blaustein's pathology of the female genital tract. New York: Springer-Verlag;1987. pp. 409-13.

[17]. Youssef AF, Fayad MM, Shafeek MA.Torsion of the fallopian tube: A clinico-pathological study. Acta Obstet Gynec Scand 1962;41:292-309. 